УДК 536.27

\title{
ОСОБЕННОСТИ РАСЧЕТА ТЕПЛООБМЕННОГО АППАРАТА ДЛЯ УТИЛИЗАЦИИ ТЕПЛОТЫ СТОЧНЫХ ВОД
}

\author{
Басок Б.И. ${ }^{1}$, Новицкая М.П. ${ }^{1}$, Литвинюк Ю.Н. ${ }^{2}$ \\ ${ }^{1}$ Институт технической теплофизики НАН Украины, ул. Желябова, 2а, Киев, 03057, Украина \\ ${ }^{2}$ ООО «Прогресс-XXI», ул. Василия Касияна 2/1, оф. 378 г. Киев, 03121, Украина
}

В роботі розглянуто можливість вилучення теплового потенціалу стічної каналізаційної води для теплозабезпечення будівель. Представлено приклад конструкторського розрахунку рекуперативного теплообмінного апарату, який може вилучати теплоту стічної води каналізаційного колектору. В результаті одержано, що 3 збільшенням швидкості стічної води за умови рівності інших показників збільшується середній коефіцієнт теплопередачі.
В работе рассмотрена возможность извлечения теплового потенциала сточных канализационных вод для теплообеспечения зданий. Представлен пример конструкторского расчета рекуперативного теплообменного аппарата, который может извлекать теплоту сточных вод канализационного коллектора. Получено что с увеличением скорости сточных вод при прочих равных условиях увеличивается средний коэффициент теплопередачи.
At this article the possibility of energy recuperation from waste water is considered. Example of calculation wastewater heat exchanger is represented. Decrease of the average heat transfer coefficient along with velocity reduction on assumption all other constant rates is obtained.

Библ. 6., табл. 2., рис. 2.

Ключевые слова: теплообменный аппарат, сточные воды, утилизация теплоты.

\section{Введение}

Значительную часть энергопотребления Украины (около 40 \%) составляет потребление тепловой и электрической энергии в зданиях и сооружениях. Говоря об энергосбережении в зданиях, обычно имеют ввиду их утепление либо увеличение термического сопротивления оконных конструкций, что позволяет существенно уменьшить затраты на отопление зданий. При этом часть затрат, которая приходится на горячее водоснабжение, рассматривается гораздо реже. А при современных требованиях человека к комфортному проживанию, эта часть не ограничивается только централизованным горячим водоснабжением. В современном жилье существует множество бытовых приборов генерирующих теплую воду (стиральные машины, посудомоечные машины, бойлеры горячей воды, газовые колонки и т.д.). Все это затраты тепловой энергии, прямые потери которой выбрасываются в систему канализационного водоотвода. В настоящее время возрастает интерес к системам сбора и повторного использования этой сбросной тепловой энергии. [1-6]

Сточные канализационные воды могут служить источником энергии для теплообеспечения зданий при помощи тепловых насосов. Эта технология проста и уже достаточно опробована в мире. Исследования, проведенные в Германии и Швейцарии, показали, что около 3 \% от всех зданий могут быть отоплены при помощи тепла сточных вод [1].

\section{Системы и виды существующих систем утилизации теплоты сточных вод}

Существуют разные возможности для извлечения теплового потенциала сточных вод. Вопервых, это системы, которые могут быть установлены непосредственно в домах [6]. Также теплота сточных вод может быть отобрана в канализационных коллекторах, ведущих к очистным станциям $[2,6]$. И в конечном итоге на очистных сооружениях, вариант из возможных проектных решений подобных систем представлен, например, в [3].

Одним из основных элементов в таких системах является теплообменный аппарат. Как 
правило, в системах такого типа используются теплообменные аппараты рекуперативного типа, т.е. аппараты в которых две жидкости с различными температурами текут в пространстве, разделенном твердой стенкой. Такие теплообменные аппараты могут быть классифицированы по многим критериям, таким как геометрия аппарата, направление движения жидкости, преобладающий вид теплообмена и т.д. Расчетными параметрами таких теплообменных аппаратов являются температура и расход сточных вод, разница температур между сточными водами и отводящей теплоту жидкостью, геометрические параметры сточной трубы и теплообменного аппарата, наполненность трубы сточных вод, скорости движения обоих жидкостей и т.д.

\section{Характеристики сточных вод, как источника энергии}

Сточные воды достаточно редко используются как теплоноситель, в связи с этим в научной литературе можно найти лишь небольшое количество публикаций на эту тему. При проектировании систем энергосбережения, в первую очередь интерес представляют данные о температуре и расходах воды в коллекторах сбора сбросных вод, а также данные об их теплофизических свойствах.

В работе [4] приведены подробные экспериментальные данные о температуре и расходах системы сточных вод г. Болонья, Италия с октября 2005 г. по март 2006 г. Авторы приводят данные об изменениях температуры и расходах сточный вод, их суточных и сезонных колебаниях. Средняя температура сбросных вод в г. Болонья составляет $20,9{ }^{\circ} \mathrm{C}$ в октябре и $13,5^{\circ} \mathrm{C}$ в декабре месяце. Авторы экспериментально подтвердили тот факт, что температура сбросных вод существенно зависит от расхода сточных вод и в гораздо меньшей степени зависит от температуры окружающей среды. Существенное же снижение температуры сточных вод было отмечено в сезон дождей, т.к. в г. Болонья система сточных вод объединена с ливневой системой сбора и отвода дождевой воды.

При проектировании теплообменного аппарата в [2] использовались данные о температуре сточных вод в Северном Китае, расчетное значение температуры составляло $12^{\circ} \mathrm{C}$, при этом было отмечено, что минимальное значение в зимний период может достигать значений ниже $10^{\circ} \mathrm{C}$.

В [6] высказано мнение о том, что минимальная температура сточных вод должна быть не менее $12^{\circ} \mathrm{C}$. Также приведены данные о том, что биопленка, образующаяся на стенках трубы сточных вод, снижает коэффициент теплопередачи на $50 \%$, что в свою очередь становится причиной необходимости увеличить поверхность теплообмена теплообменного аппарата.

\section{Описание исследуемого теплообменного annapama}

В данной работе рассматривается проект рекуперативного теплообменного аппарата, который может использовать теплоту сточных вод канализационного коллектора большого диаметра,

Табл. 1

\begin{tabular}{|c|c|l|c|c|}
\hline $\begin{array}{c}\text { № } \\
\text { п/п }\end{array}$ & \multicolumn{1}{|c|}{ Наименование } & Величина & Значение \\
\hline 1 & $Q$ & Тепловая мощность & кВт & 130 \\
\hline 2 & $t^{\prime}{ }_{1}$ & $\begin{array}{l}\text { Рабочая температура со стороны } \\
\text { сточных вод }\end{array}$ & ${ }^{\circ} \mathrm{C}$ & 15 \\
\hline 3 & Теплоноситель 30\% раствор воды и пропиленгликоля. & 5 \\
\hline 4 & $t_{2}^{\prime} \quad \begin{array}{l}\text { Температура 30 \% раствора воды и } \\
\text { пропиленгликоля на входе в } \\
\text { теплообменный аппарат }\end{array}$ & ${ }^{\circ} \mathrm{C}$ & 10 \\
\hline 5 & $t_{2}^{\prime \prime}$ & $\begin{array}{l}\text { Температура раствора воды и пропи- } \\
\text { ленгликоля на выходе из } \\
\text { теплообменного аппарата }\end{array}$ & ${ }^{\circ} \mathrm{C}$ & \\
\hline
\end{tabular}


схема которого представлена на рис. 1. Особенностью данной модели теплообменного аппарата является возможность его установки на существующую сточную трубу путем приваривания двух секций теплообменного аппарата с последующим проведением гидравлических испытаний. Рассматриваемый теплообменный аппарат относится к типу аппаратов «труба в трубе». В аппарате сточные воды движутся внутри трубы меньшего диаметра, а охлаждающая их жидкость в межтрубном пространстве - между трубами большего и меньшего диаметров. Жидкости движутся в противоположных направлениях, поэто- му аппарат следует относить к противоточному типу. Некоторые технические характеристики рассматриваемого аппарата приведены в табл. 1.

Для увеличения коэффициента теплопередачи от стенок металлической трубы, по которой проходит нагревающая жидкость к тепловоспринимающей жидкости, на поверхность трубы приваривается металлическая спираль, которая образует $n$ витков для движения водного раствора пропиленликоля в заданном направлении. Для подключения теплообменника предусмотрены металлические фланцы (см. рис. 1. А и Б).
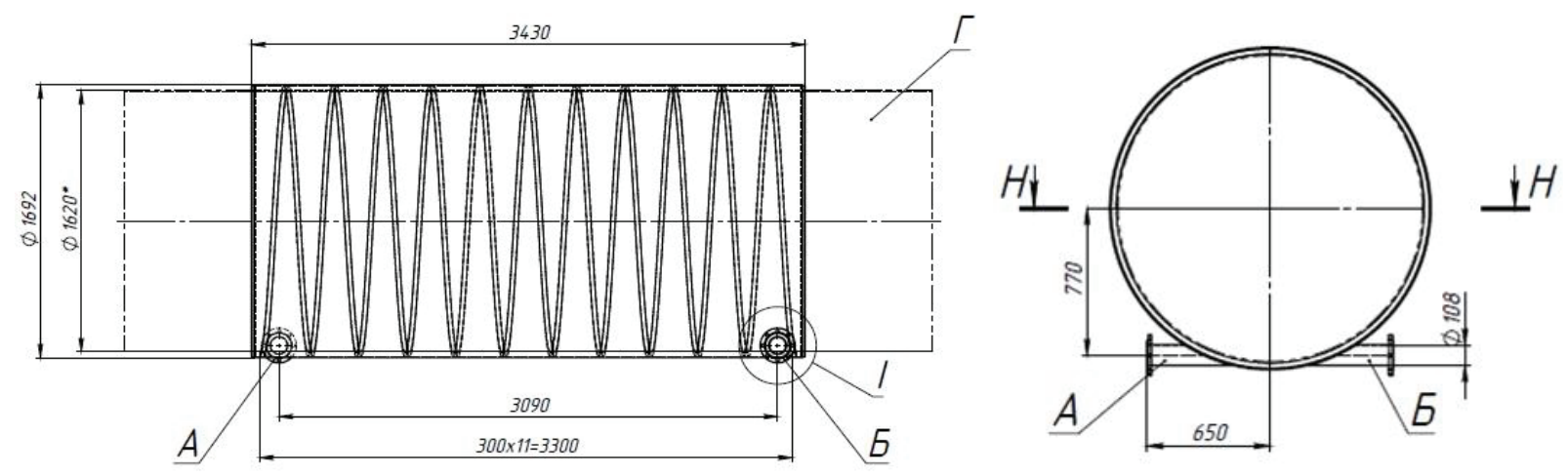

Рис. 1. Общиий вид и размеры секции теплообменника.

A - штуцер подвода теплоносителя, Б - штуцер отвода теплоносителя, Г- сточные воды, I - теплообменник.

\section{Расчетные формуль}

При расчете теплообменного аппарата такого типа, основными уравнениями являются уравнения теплопередачи и теплового баланса.

$Q=K \cdot F\left(t_{1}-t_{2}\right)$,

$Q_{1}=Q_{2}+\Delta Q$

Где $Q=\left(G c_{p}\right)_{j} \delta t_{j}$,

$G$ - расход теплоносителя, $c_{p}$ - его теплоемкость, $F$ - искомая площадь теплообменного аппарата, $K$ - коэффициент теплопередачи.

Одной из особенностей расчета можно считать определение коэффициента теплопередачи. В данной работе рассчитывался ее осредненный вариант:

$$
\bar{K}=\frac{1}{\frac{1}{\alpha_{1}}+\frac{\delta_{\text {ст }}}{\lambda_{\text {ст }}}+\frac{1}{\alpha_{2}}},
$$

где коэффициенты теплоотдачи $\alpha_{1}$ - от сточных вод к стенке трубы, и $\alpha_{2}$ - от трубы к нагреваемо- му $30 \%$ раствору воды и пропиленгликоля могут быть определены из уравнений, полученных на основе теории подобия, а более точные значения осредненного коэффициента теплопередачи могут быть получены на основе прямого численного теплофизического моделирования.

В рассматриваемом случае при турбулентном режиме движения в трубах некруглого сечения можно применить следующую формулу:

$$
\mathrm{Nu}_{i}=\frac{\alpha_{i} d_{\text {экві }}}{\lambda_{i}}=0,021 \mathrm{Re}_{i}^{0,8} \operatorname{Pr}_{i}^{0,43}\left(\frac{\operatorname{Pr}_{i}}{\operatorname{Pr}_{\text {ст }}}\right)^{0,25} \varepsilon_{1} \varepsilon_{2} .
$$

Эквивалентный диаметр трубы рассчитывается по формуле

$$
d_{\text {экві }}=\frac{4 F_{i}}{P_{i}},
$$

где $F_{\mathrm{i}}-$ Площадь поперечного сечения; $P_{\mathrm{i}}-$ его смачиваемый периметр; $\varepsilon_{1}$ - поправка, учитывающая изменения среднего коэффициента тепло- 
отдачи по длине трубы; $\varepsilon_{2}-$ поправка, учитывающая центробежные силы.

При этом следует отметить следующую особенность: в связи с тем, что труба сточных вод проектируется таким образом, что ее наполненность варьируется от 0,3 до 0,8 (см. рис. 2.) площадь поперечного сечения трубы сточных вод необходимо рассчитывать с учётом этого факта. В нижеприведенных таблицах даны основные расчетные данные конструкторского расчета теплообменного аппарата такого типа при различных скоростях движения сточных вод и средней наполненности трубы 0,6 (табл. 2) в трубе диаметром 1,62 м.

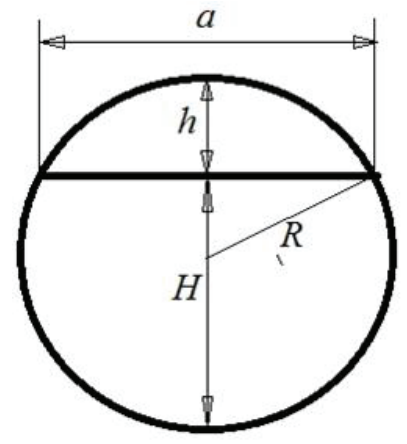

Рис. 2. Сечение трубы сточных вод.

Н-высота наполненности трубы;

h-высота пустой части сегмента;

$R$ - внутренний радиус трубы;

а-длина хорды.

Табл. 2. Данные расчета теплообменного аппарата

\begin{tabular}{|l|c|c|c|c|c|c|c|}
\hline Наименование & $\begin{array}{c}\text { Обозна- } \\
\text { чение }\end{array}$ & \multicolumn{1}{|c|}{$\begin{array}{c}\text { Вели- } \\
\text { чина }\end{array}$} & \multicolumn{5}{|c|}{ H/D=0.6 } \\
\hline Скорость & $v$ & $\mathrm{M} / \mathrm{c}$ & 0,5 & 0,7 & 0,9 & 1,2 & 1,5 \\
\hline $\begin{array}{l}\text { Осредненная температура } \\
\text { стенки со стороны сточных вод }\end{array}$ & $t_{\text {ст1 }}$ & ${ }^{\circ} \mathrm{C}$ & 12,3 & 13,2 & 13,4 & 13,7 & 13,9 \\
\hline Число Нуссельта & $\mathrm{Nu}_{1}$ & & 2384 & 3129 & 3832 & 4834 & 5788 \\
\hline $\begin{array}{l}\text { Коэффициент теплоотдачи } \\
\text { со стороны сточных вод }\end{array}$ & $\alpha_{1}$ & $\mathrm{~B} / \mathrm{M}^{2} \mathrm{~K}$ & 1132 & 1487 & 1821 & 2297 & 2750 \\
\hline $\begin{array}{l}\text { Осредненная температура стенки } \\
\text { со стороны тепловоспринимающей } \\
\text { жидкости }\end{array}$ & $t_{\text {ст2 }}$ & ${ }^{\circ} \mathrm{C}$ & 6,9 & 7,1 & 7,2 & 7,3 & 7,4 \\
\hline Число Нуссельта & $\mathrm{Nu}_{2}$ & & 127 & 127 & 127 & 127 & 127 \\
\hline $\begin{array}{l}\text { Средний коэффициент теплоотдачи } \\
\text { стороны тепловоспринимающей } \\
\text { жидкости }\end{array}$ & $\alpha_{2}$ & $\mathrm{Bт} / \mathrm{M}^{2} \mathrm{~K}$ & 1229 & 1234 & 1233 & 1234 & 1236 \\
\hline Коэффициент теплопередачи & $K$ & $\mathrm{M}^{2} \mathrm{~K} / \mathrm{BT}$ & 341 & 368 & 386 & 408 & 416 \\
\hline $\begin{array}{l}\text { Площадь поверхности } \\
\text { теплообмена }\end{array}$ & $F$ & $\mathrm{M}^{2}$ & 53 & 49 & 46 & 45 & 43 \\
\hline
\end{tabular}

\section{Выводы}

1. Увеличение скорости сточных вод при прочих равных условиях увеличивает средний коэффициент теплопередачи, и, в свою очередь, уменьшает расчетную площадь теплообмена, необходимую для получения заданной тепловой мощности теплообменного аппарата.
2. Оценочный расчет площади теплообменного аппарата необходимо проводить, основываясь на минимальной скорости сточных вод.

3. Более точные значения осредненного коэффициента теплопередачи могут быть получены на основе численного теплофизического моделирования, например, с помощью коммерческих компьютерных пакетов. 


\section{ЛИТЕРАТУРА}

1. F. Schmid. Sewage water: interesting heat source for heat pumps and chillers, Energy-engineer FH, Swiss Energy Agency for Infrastructure Plants, Zurich, Switzerland, 2009.

2. Z. Zhuang, D.Sun. Design and calculation of the sewage heat exchanger based on SCILAB. 2009 IEEE International Workshop on Open-source Software for Scientific Computation.(OSSC), 2009, P. $148-152$.

3. Басок Б.І. Аналіз технічних характеристик теплонасосної станції, що використовує низькопотенційну теплоту стічних вод Бортницької станції аерації для теплопостачання житлових мікрорайонів «Осокорки» $\mathrm{i}$ «Позняки» м. Києва. Б. І. Басок, М. Ю. Швець, А. А. Барило [та ін.]. Промышленная теплотехника. - 2011. -
T. 33, № 6. - C.58-63.

4. S.Sipolla., M. Maglionico. Heat Recovery from Urban Wastewater: Analysis of the Variability of Flow Rate and Temperature in the Sewer of Bologna, Italy. Energy and Buildings 69 (2014), pp. $122-130$.

5. L. Postrioti, G. Baldinelli, F. Bianchi, G. Buitoni, F.Di Maria, F. Asdrubali. An experimental setup for the analysis of an energy recovery system from wastewater for heat pumps in civil buildings. Applied Thermal Engineering 102 (2016), P. 961971

6. D. Stransky I. Kabelkova, V. Bares, G. Stastna, Z. Suchorab. Suitability of combined sewers for the installation of heat exchangers. Ecological Chemistry and Engineering Volume 23, Issue 1, P. 87-98. 


\section{CHARACTERISTIC OF HEAT EXCHANGER CALCULATION FOR WASTEWATER HEAT RECOVERY}

\section{Basok B.I. ${ }^{1}$, Novitska M.P. ${ }^{1}$, Litvinuk Y.N. ${ }^{2}$}

1 Institute of Engineering Thermophysics of the National Academy of Sciences of Ukraine, 2a, Zhelyabova str., Kyiv, 03057, Ukraine

2 OOO «Прогресc-XXI», 2/1. Basil Kasiyan st, Kyiv, 03121, Ukraine

At this article the possibility of energy recuperation from waste water is considered. Example of calculation wastewater heat exchanger is represented. The heat balance and heat transfer equation was used to calculate counter flow heat exchanger. The heat transfer coefficient was fined with empirical correlation equation for heat transfer. On assumption all other constant rate the decrease of the average heat transfer coefficient along with velocity reduction was obtained. References 6, tables 2, figures 2.

Key words: heat exchanger, wastewater, heat recovery.

1. F. Schmid. Sewage water: interesting heat source for heat pumps and chillers, Energy-engineer FH, Swiss Energy Agency for Infrastructure Plants,
Zurich, Switzerland, 2009.

2. Z. Zhuang, D. Sun. Design and calculation of the sewage heat exchanger based on SCILAB. 2009 IEEE International Workshop on Open-source Software for Scientific Computation.(OSSC), 2009, P.148-152.

3. Basok B.I. Technical parameters analysis of a heat-pump unit based on low-potential sewage waters utilization at Bortnychi aeration plant for heat supply in Osokorky and Poznyaky regions of Kyiv. Basok B.I. at all. Promyshlennaya teplotekhnika. 2011. - V. 33, № 6. - P.58-63. (Ukr.)

4. S. Sipolla., M. Maglionico. Heat Recovery from Urban Wastewater: Analysis of the Variability of Flow Rate and Temperature in the Sewer of Bologna, Italy. Energy and Buildings 69 (2014). P. $122-130$

5. L. Postrioti, G. Baldinelli, F. Bianchi, G. Buitoni, F. Di Maria, F. Asdrubali. An experimental setup for the analysis of an energy recovery system from wastewater for heat pumps in civil buildings. Applied Thermal Engineering 102 (2016). P. 961971

6. D. Stransky I. Kabelkova, V. Bares, G. Stastna, Z. Suchorab. Suitability of combined sewers for the installation of heat exchangers. Ecological Chemistry and Engineering Volume 23, Issue 1, P. 87-98. 